\title{
MATHEMATICAL MODELING OF VIBROBURNISHING OF THE HOLE OF CYLINDER
}

\author{
Tatyana Nikonova $^{1^{\star}}$ Gulnara Zhetessova ${ }^{2}$ Vasiliy Yurchenko ${ }^{2}$ \\ ${ }^{1}$ S. Seifullin Kazakh AgroTechnical University, Astana, Kazakhstan \\ ${ }^{2}$ Karaganda State Technical University, Karaganda, Kazakhstan
}

The authors obtained dependencies of the surface layer properties after machinig cylinder holes by vibroburnishing. The properties of the surface layer are changed from a variety of vibroburnishing factors. Surface layer quality graphics of the machining parameters are obtained by mathematical modeling using formulas derived empirically. During the processing of experimental data, the authors of the articles identified optimal processing regimes in which parameters of the quality of the surface layer of the billet can be specified. Thus, vibroburnishing is better to make machining on the mode: $m=16,5 \mathrm{~mm}, i=1,7 \mathrm{~mm}, \alpha=7,5^{\circ}, A y=160 \mathrm{~J}, f=20 \mathrm{~Hz}$. It was found that the greater vibroburnishing tightness is, the greater the value of size of the cold-hardening layer is. Rougher surface will always have bigger tightness of burnishing, i.e. the purer surface is, the lower the value of tightness of a vibroburnishing must be. However, in the process of a vibrational burnishing of holes there is a so-called critical point, roughness of a surface decreases and the surface layer of metal is strengthened before reaching this point, and after reaching it there is a phenomenon of a re-cold-hardening and quality of a surface decreases.

Key words: Tight, Surfaces, Property, Processing, Machining, Layers, Holes, Cylinder

\section{INTRODUCTION}

The agro-industrial complex of the Republic of Kazakhstan (AIC of KZ) occupies a considerable part of the gross domestic product (GDP) and is one of the priority industries of national economy. At the same time productivity improvement of agricultural sector depends on mechanization and automatization of operations. Mechanization of operations is generally reached due to the use of the attached equipment of agricultural machines. The main drive of mechanisms of the attached equipment is the hydraulic drive. The main type of damages of hydraulic drives is breaking or misoperation of the hydraulic cylinders which are components of hydraulic drives, i.e. the change of geometrical dimensions, wear or disintegration of a working surface of cylinder.

Researches and practice of operation of hydraulic cylinders show that surfaces of machine parts are exposed to the greatest stress while inside layers of metal do not experience that load. Upper layers resist to wear, corrosion, thermal effect, etc. Therefore such scientific direction as the increase in accuracy and reliability of machines by technological methods providing significant increase in hardness and wear resistance of working surfaces of hydraulic cylinders is being intensively developed.

Development of a technology and new tools, methods of the choice of the optimum modes for machining and hardening of a surface layer are an effective opportunity of achievement of required quality of working cylinder surfaces. The last will allow to increase the interrepair period by $15-20 \%$, to increase operational properties (such as resistance to wear, corrosion and thermal effect) due to the change of a surface layer structure.
One of the main solutions of this task is vibration hardening of a surface layer of made parts (vibroburnishing). The use of surface plastic deformation is highly effective means of reduction of surface roughness, formation of residual tension of compression in a surface layer of parts, increase in superficial hardness and wear resistance which leads to substantial increase of machine reliability. The solution of such task aspects as mechanics of interaction of the processing tool with a surface of the processed parts, influence of parameters of vibration fluctuations on a condition of the machinable material, design of vibration installations and tools, influence of conditions of vibroburnishing on the quality of a surface and operational properties of hydraulic cylinders, development of new technological and kinematic schemes is necessary [01].

Many scientists such as M. Korzynski [02], Gheorghe Nagît [03] and others, are currently carrying out research on how various factors of the vibration process affect the main indicators of the quality of the surface layer of machine parts. At the Polish university from Rzeszow, Professor M. Korzynski collaborators developed and received various equipment for vibration processing and also investigated aspects concerning the results of this processing method.

New way of hardening of SPD is static and impulse machining (SIP) which due to impact on the strengthened surface of the operated waves of deformation has ampler opportunities on formation of the layer strengthened superficially with a depth (to $6 . . .8 \mathrm{~mm}$ ) and high degree of hardening (to $6500 \mathrm{MPas}$ ). The SIP technology allows to regulate uniformity of hardening, creating both evenly and heterogeneously strengthened structure. 
At SIP plastic deformation of the strengthened material is carried out by impulse loading which is the result of occurrence in an impact system at the impact of wave deformation and run by geometrical parameters of an impact system. The static component of loading does not practically participate in the process of elastic and plastic deformation and is intended for the fullest use of impulse one. As a result, the strengthened surface consists of plastic prints which are blocked among themselves in a certain order [04].

The vibroburnishing of holes allows to reduce errors of thermal processing in comparison with a static burnishing at the expense of a deformation process intensification. At the same time considerable specifications of errors take place at burnishing of holes in the volume tempered parts.

The combined static and dynamic loadings of the center of deformation allow to use the energy of an impact impulse more fully. As a result of static and impulse loading of flat and figurine surfaces the strengthened surface layer with a high depth and degree of hardening is provided [05].

The vibrational burnishing needs 2.2 times less energy, than a static burnishing that promotes increase in productivity of the process.

The scheme of a hole burnishing by means of the device having the combined deforming tool with static and impulse loading is given in Figure 1.

This device serves for burnishing, i.e. calibration of holes, which is operation for machining of holes of machine parts by surface plastic deformation. This operation is carried out by movement with a tightness of the deforming tool (burnisher 1), a built-up construction to which constant static and periodic impulse loadings along the processed hole surface is given.

A workpiece 2 is placed on the plate 3 fixed on the table of the working machine, and the burnisher 1 is put into the machined workpiece hole. Machining starts with switching on of longitudinal feed Spr which is performed due to constant effect of a duct 4 on the burnisher 1 . The duct 4 is under the main static load Pst and additional periodic impulse load Pim. The last is performed by means of the pane 5 affecting the butt end of the duct 4 , made in the form of cores of identical diameter. The hydraulic generator of impulses is used as the mechanism of impulse loading of the tool.

Static loading $\mathrm{P}_{\mathrm{st}}$ and longitudinal feed $\mathrm{S}_{\mathrm{pr}}$ of the duct 4 and the burnisher 1 are performed by means of a hydraulic cylinder of static loading 6 where piston 7 is firmly joined to the holder 9 of the hydraulic generator of impulses $(\mathrm{HGI})$ by the rod 8 . The duct 4 is placed in the holder 9 having possibility of longitudinal axial movement and contains a patch with the plunger 10 placed in it and in the holder 9 . Plunger 10 prevents a longitudinal axis crank.

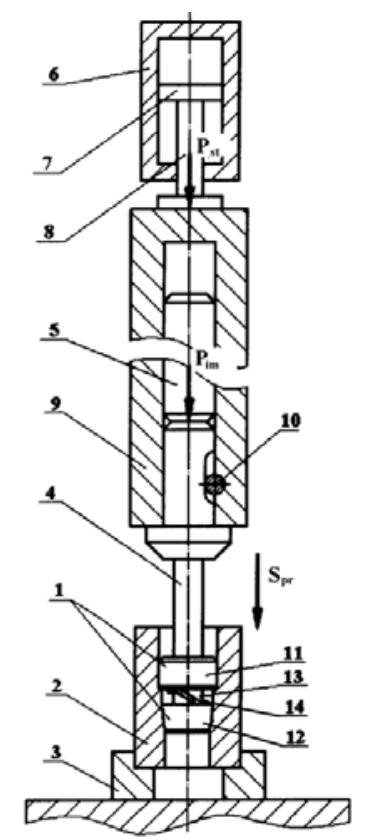

Figure 1: Scheme of a vibroburnishing

The burnisher 1 consists of two parts: a stationary part 11 which is firmly fixed on a duct 4 and moving part 12 which is coaxially placed on a stationary part. Coaxiality of two parts of a burnisher is performed by means of the centering plug 13 belonging to a moving part which enters the central hole on the sliding landing of a stationary burnisher part.

Moving part 12 of a burnisher is joined to a stationary part 11 by means of laminated spring 14 . Laminated springs 14 have Z-shaped form which enables to give returnable and rotary and reciprocating movements of longitudinal axis to a moving part in the longitudinal direction. One end of the laminated spring 14 is firmly joined to a moving part, and another end is joined to a stationary part. Springs are made of the steel cold-drawn thermoprocessed tape. The quantity of laminated springs 14 in a set depends on the dimension of a burnisher and the machined workpiece hole.

In assembled form, radial beat of the deforming parts of the burnisher should not exceed $0.02 \ldots 0.05 \mathrm{~mm}$. The working form of the moving deforming part 12 represents a truncated cone with an angle $3^{\circ} \ldots 5^{\circ}$, and the working form of the stationary part 11 represents the cylindrical surface acting as the calibrating ribbon. Width of a cylindrical surface is counted on a formula:

$$
b=0.35 d \cdot 0.6
$$

where $b$ is width of a cylindrical surface of a stationary part 11 of the burnisher, $\mathrm{mm}$; $\mathrm{d}$ is a diameter of a machined hole, $\mathrm{mm}$.

When machining parts of machines by means of vibroburnishing, application of the lubricant cooling technological means preventing seizure of forming elements with the machined metal (which leads to the spoilage of the machined parts and to destruction of the deforming 
elements) is necessary. Sulfofrezol, MR-1, MR-2, emulsions are used for parts made from carbon and low-alloy steels, from non-ferrous metals (bronze, brass, aluminum alloys).

\section{MAIN PART}

Vibroburnishing is carried out by the use of a constant static $P_{\text {st }}$ and periodic impulse $P_{\text {im }}$ loadings.

Impulse loading $P_{\text {im }}$ is carried out by means of pane impact of the hydraulic pulse generator on a duct butt end.

The pane is restored in original position after cancellation of impact energy on the tool and relieving of a static loading.

The initial pulse formed in the pane at the moment of impact on the duct, reflecting from the free butt end of the pain with an opposite sign, reaches the duct, one its part is reflected in the pane, and another one passes into a duct and extends in the direction of the loaded surface. Impact and opposite directed pulses have identical amplitudes and durations, each of them will influence a machinable surface with circularity, equal to the double duration of pulses. Having reached a machinable surface, impact pulse is distributed on passing and reflecting pulses. The passing pulse generates a dynamic component of deformation force [01].

The vibrational burnishing of holes allows to reduce errors of heat treatment in comparison with a static burnishing more considerably due to intensification of the process of deformation. Thus big specifications of errors take place in case of burnishing of holes in the volume hardened workpieces.

Process of a vibroburnishing of holes is characterized by the following indicators, factors and dimensions influencing the quality of a surface:

- relative thickness of a wall of workpiece m:

- a corner of an intaking cone of the tool $\alpha, \stackrel{\circ}{\text {; }}$

- tool geometry;

- brand of material of a machinable workpiece;

- tool material brand;

- scheme of deformation;

- tightness of vibroburnishing $i, \mathrm{~mm}$;

- $\mathrm{h}$ - size of cold hardening, $\mathrm{mm}$;

- preliminary machining of a hole;

- frequency of impacts $f, \mathrm{~Hz}$;

- impact energy $A_{y}, \mathrm{~J}$;

- forcing of static preload of the tool to workpiece $\mathrm{P}_{\mathrm{st}}$;

- greasing in the course of vibroburnishing;

- friction coefficient.

All above-mentioned characteristics can be conditionally united in 4 main groups to consider their influence on vibroburnishing process in general.

The first group is the physical and mechanical indicators including brand of material of a tool and a workpiece. Physical and mechanical properties of the machinable material effect hardness, the size of a cold-hardening layer and micro geometry of a surface of the machined product. Mechanical properties of tool material substantially determine technological capabilities of the process and operational capabilities of a machine part after vibroburnushing. Both of these parameters influence roughness and hardness of a surface layer of the machined workpiece.

A corner of an intaking cone $\alpha$, width of a cylindrical ribbon $b$, a number of burnishing teeth $z$ belong to the second group.

The corner of an intaking cone $\alpha$ influence roughness of a surface and a size of the cold-hardening layer, thus the increase of $\alpha$ effect a cold-hardening size. The indicator of roughness and the cold-hardening layer improves with the increase of $b$.

The third group is the strength indicators determining physics of the process both before interaction of the tool with a workpiece and during burnisher passing through a hole. The third group includes the scheme of deformation, relative thickness of the wall $m$, tightness size $i$ and a size of cold-hardening layer $h$. Hardness and a size of a cold-hardening layer increase with the increase in thickness of the wall $m$ and tightness $i$. In this group, roughness is mainly effected by the scheme of burnishing and a size of tightness.

Preliminary machining of a hole, frequency of impacts $f$, force of static waisting of the tool $\mathrm{P}_{\mathrm{st}}$, energy of impact $A_{y}$, lubrication in the process of machining belong to the fourth technological group of indicators. The result of surface machining will directly depend on the right choice and the accounting of this group of indicators. Calculation, design and modeling of the whole vibroburnishing process are reduced to the analysis and assignment of this group of indicators.

Preliminary machining influences all three considered properties of a surface layer improving them.

Increase in frequency of impacts leads to decrease of the roughness, increase of hardness and increase in the col-hardening layer that positively affects workpiece machining.

The size of static preload directly influences the roughness and hardness of a surface. It is impossible to predict favorable or negative impact of increase in size of $P_{\text {st }}$ on properties of a surface layer. Complexity of determination of optimum size of static forcing is caused by the fact that it depends on a large number of the interconnected factors (mechanical properties of the machinable material, the sizes of the harhened workpiece and a size of a tightness, etc.)

With increase of Pst the size of the transferred energy increases and a degree of deformation raises, the smoothing of microroughnesses occurs. At further increase of $\mathrm{P}_{\mathrm{st}}$ in a surface layer, there is the tension, bigger than the 
strength that leads to a re-cold-hardening and decrease in purity of a surface.

Increase in impact energy provides increase in depth of a cold-hardening.

\section{RESULT}

The scientific study of the process of plastic deformation of the internal cylindrical surfaces can be done theoretically or experimentally. In modern conditions of development of science and technology integrated study of the object is more preferable. This can be achieved on the basis of a new, fitting the requirements of the time methodology and research technology.

Computing experiment of the process of vibroburnishing of holes begins when sifficient data for formation of a mathematical model is obtained as a result of full-scale experiment. Usually designed mathematical model is so complicated that it is required to design not only the unique software for its reproduction on the computer, but also new numerical methods to find the solution in acceptable time limits and with a necessary accuracy.

Researches of the roughness received as a result of vibroburnishing of holes are conducted. Researches were conducted on samples from steel 45 with the following sizes: length of a hole is $50 \mathrm{~mm}$, an inside diameter $15 \ldots$ $30 \mathrm{~mm}$, outer diameter $28 . .50 \mathrm{~mm}$, thickness of a wall $4,5 \ldots 16,5 \mathrm{~mm}$. As a result, machining occurred with tightness varying in the range $\mathrm{i}=0,3 \ldots 1,7 \mathrm{~mm}$. Macining took place under the following conditions: impact energy $A_{y}=100 \ldots 250 \mathrm{~J}$, impact frequency $f=5 \ldots 25 \mathrm{~Hz}$, the power of static compression $\mathrm{P}_{\mathrm{st}}=40 \mathrm{kN}$.

Quality of a surface of the samples machined by vibroburnishing is influenced by a large number of factors of technological process. According to preliminary experiments and the analysis of literature five variable factors characterizing conditions of preparation of a surface for vibroburnishing and conditions of holes vibroburnishing process were selected:

1. $x 1-$ an angle of an intaking cone, degree $(\alpha)$;

2. $x 2$ - tightness, $\mathrm{mm}(\mathrm{i})$;

3. $x 3$ - impact energy $A_{y}$;

4. $x 4$ - relative thickness of a wall, $(m=D / d)$;

5. $\times 5$ - frequency of impacts $f$.

By the technique given in [01], the combined square for a five-factorial complex has been constructed. Intervals of a variation of factors were chosen according to literature and preliminary experiments [04] so that monotonous changes of the studied indicators of a surface quality of the cylinder appeared in these limits.

The following parameters of quality of a surface layer were analyzed:

1. $y_{R a}-a$ roughness of the machined surface, Ra, micron;

2. $\mathrm{y}_{\mathrm{HB}}$ - hardness according to Brinell $\mathrm{NV}, \mathrm{MPa}$;

3. $y_{h}$ - depth of a cold-hardening layer $h, m m$;
On the basis of the received mathematical dependences $(2,3,4)$, boundary conditions, values of arguments we receive the final mathematical equations of process of plastic deformation of hydraulic cylinder holes and graphics of dependences of qualitative parameters on the corresponding parameters of machining (Figure 2-8).

$$
\begin{aligned}
& y_{R a}=\left[\begin{array}{l}
\left(\frac{4.2}{x_{1}}-0.3\right)+ \\
+\left(19.4 \cdot e^{-2.74 \cdot x_{2}}\right)+ \\
+\left(18.1 \cdot e^{-0.02 \cdot x_{3}}\right)
\end{array}\right] \times\left[\left(\frac{13.5}{x_{4}}-0.65\right)+\left(3.5 \cdot e^{-0.08 \cdot x_{5}}-0.29\right)\right] \\
& y_{H B}=\left[\left(\frac{x_{1}}{2.5 \cdot 10^{-3}+3.547 \cdot 10^{-3} \cdot x_{1}}\right)+\left(0.23 \cdot 10^{3}+9.26 \cdot\left(x_{2}\right)^{3.2}\right)\right] \times \\
& \times\left(\frac{93 \cdot x_{3}}{11+0.3 \cdot x_{3}}\right)+\left(162 \cdot x_{4}^{0.17}+25\right)+\left(\frac{x_{5}}{5.5 \cdot 10^{3}+3.25 \cdot 10^{3} \cdot x_{5}}\right)
\end{aligned}
$$

$y_{h}=\left[\left(0.02 \cdot x_{1}^{2}+0.06 \cdot x_{1}+1.27\right)+\left(0.09 \cdot x_{2}^{2}+0.12 \cdot x_{2}+1.34\right)\right] \times$

$\times\left[\begin{array}{l}\left(1.14 \cdot e^{0.0016 \cdot x_{3}}+0.091\right)+\left(0.51 \cdot \lg x_{4}+1.08\right)+ \\ +\left(1.238+0.0243 \cdot x_{5}\right)\end{array}\right]$

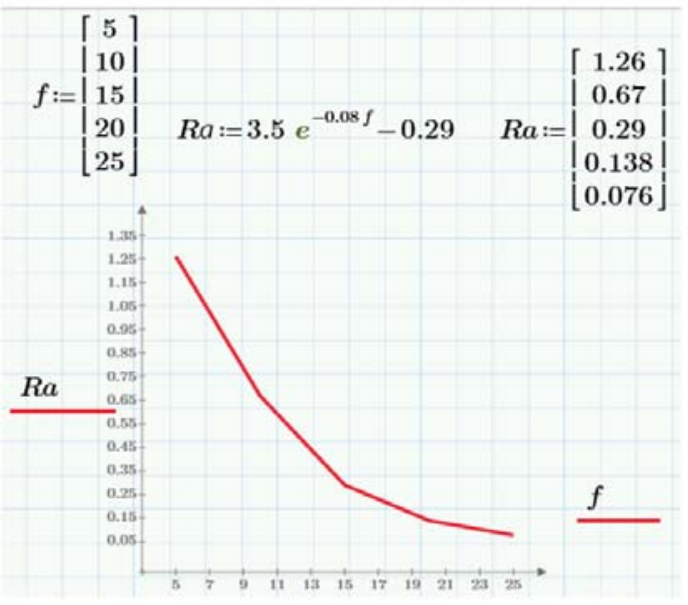

a)

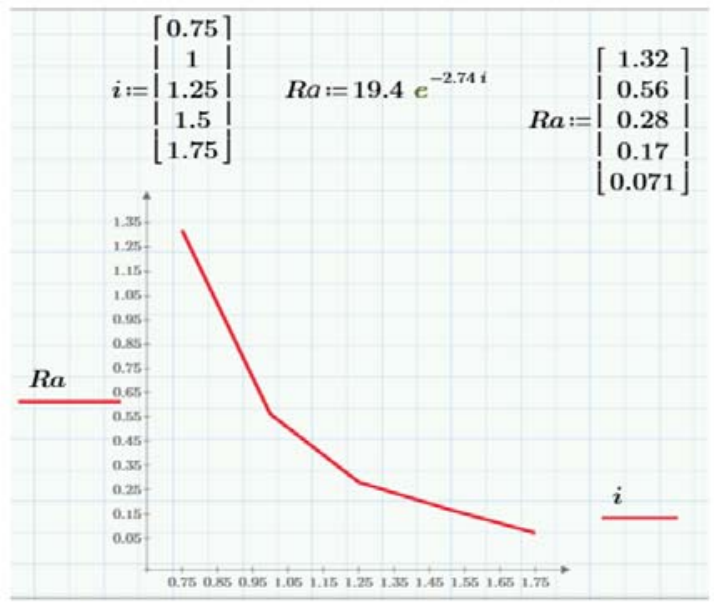

b)

Figure 2: Diagrams of dependence of a roughness of a surface after process of vibrational machining a) from value of tightness (i, $\mathrm{mm})$; b) from the frequency of impacts $(f, \mathrm{~Hz})$ 


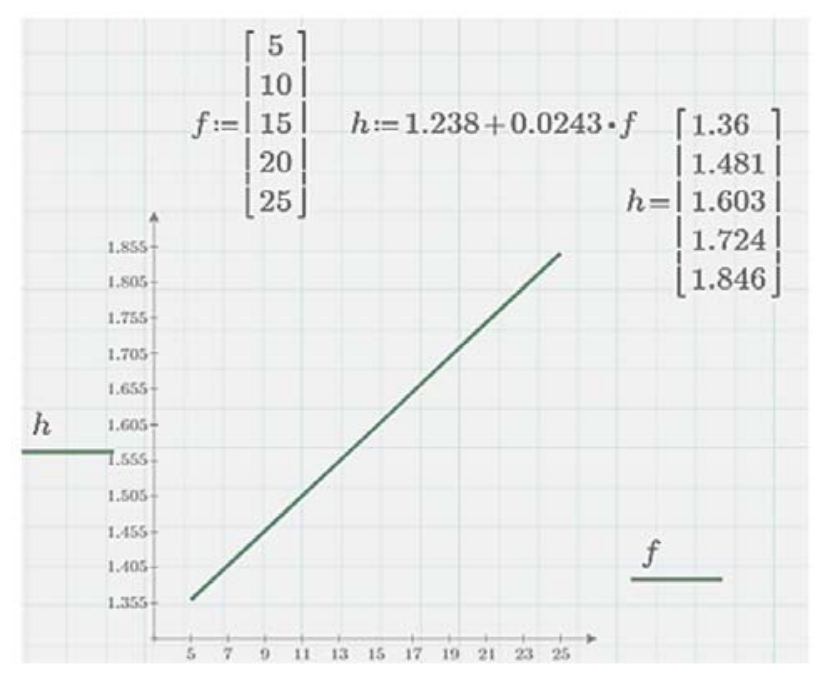

Figure 3: Diagram of dependence of depth of hardening $(h, \mathrm{~mm})$ from frequency of impacts $(f, \mathrm{~Hz})$

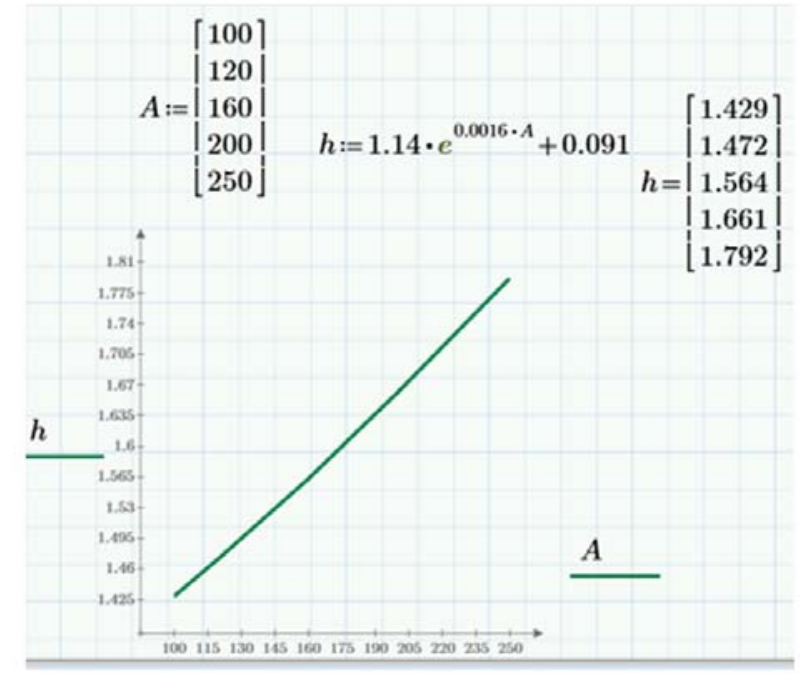

Figure 4: The schedule of dependence of depth of hardening $(h, \mathrm{~mm})$ from energy of impacts $(A, J)$

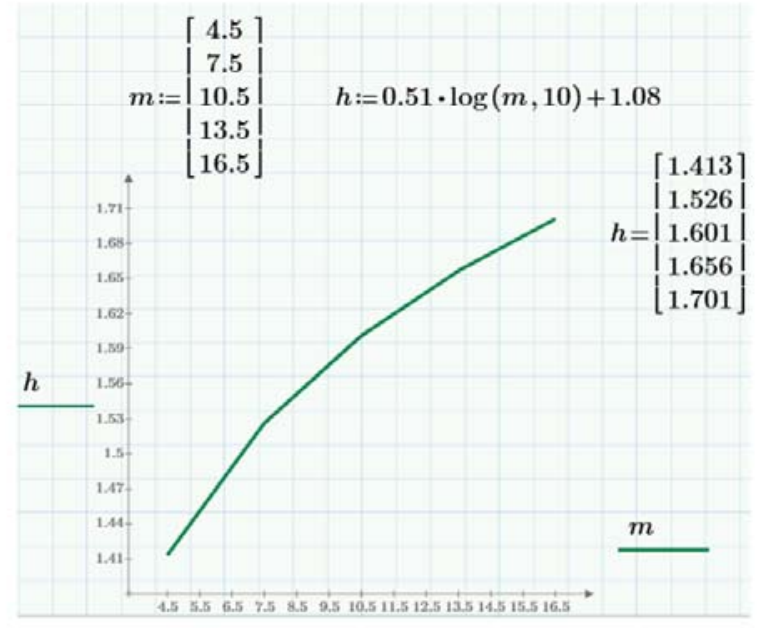

Figure 5: The schedule of dependence of depth of hardening $(h, \mathrm{~mm})$ from the relative thickness of a wall $(\mathrm{m})$

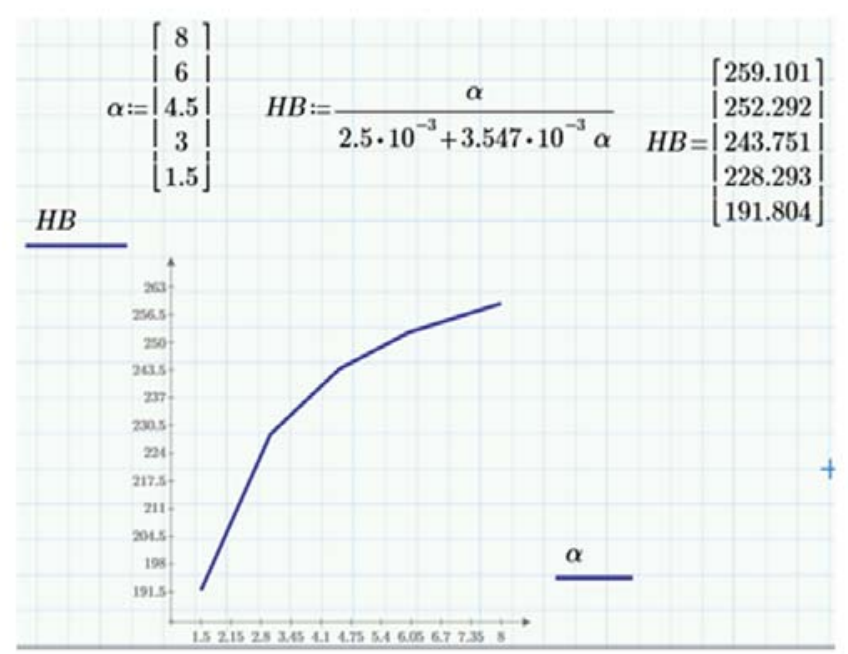

Figure 6: The schedule of dependence of hardness of a surface layer after vibrational machining from a corner of an intaking cone $\alpha{ }^{\circ}$

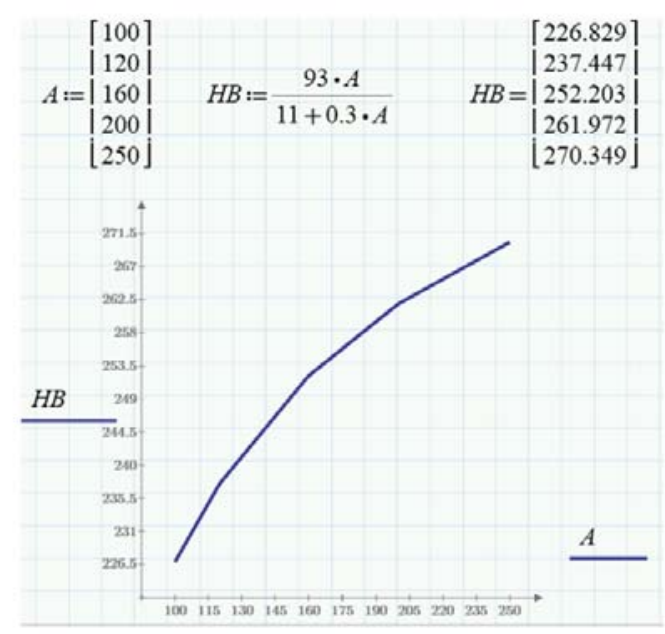

Figure 7: The schedule of dependence of hardness of a surface layer of a hole after vibrational machining from energy of impacts $(A, J)$

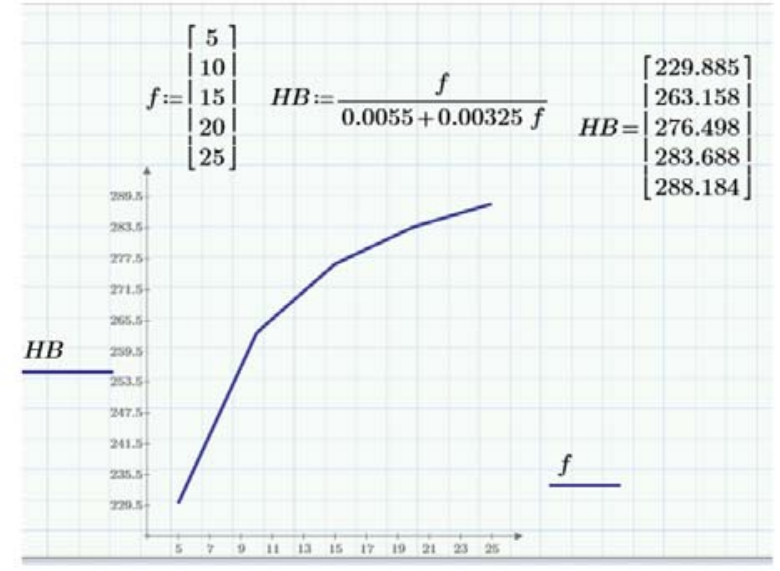

Figure 8: Diagram of dependence of hardness of a surface layer of a hole after vibrational machining from the frequency of impacts $(f, \mathrm{~Hz})$ 


\section{CONCLUSION}

The roughness is improved with the increase in a corner of an intaking cone of a vibroburnisher to $7,5^{\circ}$, in case of increase in value of a corner of an intaking cone over $7,5^{\circ}$ roughness is not improved therefore in planning of expePiment the value of a corner of an intaking cone more than $7,5^{\circ}$ was not considered.

The initial roughness of the researched internal surfaces of samples measured by the Rz parameter was changed in the range $80 \ldots 8,0$ microns. As a result of a vibroburnishing of holes in the set range it was founf out that depending on changes of frequency and energy of an impact, tightness and thickness of a wall of a sample the received roughness reached $\mathrm{Ra}-2,5 \ldots 0,16$ microns. The maximum roughness of $\mathrm{Ra}=1,25$ microns was received with tightness $\mathrm{i}=0,3 \mathrm{~mm}$, at wall thickness $\mathrm{m}=$ $16,5 \mathrm{~mm}$. The minimum roughness $\mathrm{Ra}-0,065$ microns was received in case of $i=1,25 \mathrm{~mm}$ and $\mathrm{m}=15 \mathrm{~mm}$.

Increase in tightnesses first reduces and then again increases roughness under equal conditions to certain limits. The parameter of roughness for wall thickness $\mathrm{m}=15 \mathrm{~mm}$ is $\mathrm{Ra}=0,32$ microns, if tightness $\mathrm{i}=0,2 \mathrm{~mm}$; if $\mathrm{i}=0,7 \mathrm{~mm}, \mathrm{Ra}=0,16$ microns; if $\mathrm{i}=1,25 \mathrm{~mm}, \mathrm{Ra}=$ 0,08 microns.

Increase in thickness of a wall first reduces and then increases roughness to certain limits. When machining with tightness $i=0,9 \mathrm{~mm}$ and wall thickness $\mathrm{m}=7,5 \mathrm{~mm}$, $\mathrm{Ra}=0,16 \mathrm{mkm}$; and if $\mathrm{m}=20 \mathrm{~mm}, \mathrm{Ra}=0,16$ microns.

Increase in frequency of impacts improves the quality of a surface under other equal conditions. So when machining with $\mathrm{m}=16,5 \mathrm{~mm} ; \alpha=4,5^{\circ} ; \mathrm{i}=1,35 \mathrm{~mm}$, increase in frequency led to decrease in roughness. If $f=5 \mathrm{~Hz}$, $\mathrm{Ra}=1,25$ microns; if $f=10 \mathrm{~Hz}, \mathrm{Ra}=0,63 \mathrm{mkm}$; if $f=15$ $\mathrm{Hz}, \mathrm{Ra}=0,32 \mathrm{mkm}$; if $f=20 \mathrm{~Hz}, \mathrm{Ra}=0,16 \mathrm{mkm}$.

Increase in energy of impacts also improves a surface quality. Values of energy of impacts were ranged $\mathrm{Ay}=$ $100 \ldots 250 \mathrm{~J}$. If $A y=100 \mathrm{~J}, \mathrm{Ra}=1.5$ microns, $\mathrm{h}=1,39$ $\mathrm{mm}$. If $A y=250 \mathrm{~J}, \mathrm{Ra}=0.08 \mathrm{mkm}, \mathrm{h}=1,61 \mathrm{~mm}$.

Thus, vibroburnishing is better to make machining on the mode: $\mathrm{m}=16,5 \mathrm{~mm}, \mathrm{i}=1,7 \mathrm{~mm}, \alpha=7,5^{\circ}$, Ay $=160 \mathrm{~J}$, $f=20 \mathrm{~Hz}$.

Increase in energy of impact involves increase in force of a pulse and, respectively, to the best smoothing of microroughnesses. Increase in energy of impact is directly proportional to depth of hardening and hardness of the machined layer.

It is obvious that the greater vibroburnishing tightness is, the greater the value of size of the cold-hardening layer is. Rougher surface will always have bigger tightness of burnishing, i.e. the purer surface is, the lower the value of tightness of a vibroburnishing must be.
However, in the process of a vibrational burnishing of holes there is a so-called critical point, roughness of a surface decreases and the surface layer of metal is strengthened before reaching this point, and after reaching it there is a phenomenon of a re-cold-hardening and quality of a surface decreases.

\section{REFERENCES}

1. Babishev A.P., Ryabchi Y., Hamkada H. Vibratory (vibration) shaving processing of detailers in conditions of remain productions. 5 the International Conference on Deburring and Surface Finishing, California, Sept.- San Francisco, 1998.

2. Nagîţ G., Slătineanu1 L. and others. Surface roughness at vibroburnishing. AIP Conference Proceedings, 2017.

3. M. Korzynski and J. Lubas. Bushing texturing by burnishing, in Nonconventional finishing technologies, Polish Scientific Publishers PWN, Warsaw, 2013.

4. Andersson O. Experiment! : Planning, Implementing and Interpreting. Wiley, 2012. - 288 p.

5. Skvortsov V.F., Arlyapov A.Y.: Dorning of deep small diameter holes. Monograph. - Tomsk: TPU Publishing. - 2005. - P. 92.
Paper submitted: 28.04.2017.

Paper accepted: 06.12.2017.

This is an open access article distributed under the CC BY-NC-ND 4.0 terms and conditions. 